\title{
NOTES ON THE FRANKFORT ELECTRICAL EXHIBITION.
}

BY CARL HERING.

The list of the international electrical exhibitions which have been held so far, begins with the one in Paris in 1881; this was followed by the one in Munich in 1882, then in Vienna in 1883, and Philadelphia in 1884, which was the last of this annual series of exhibitions. After a lapse of five years, during which time there were none of importance, it was followed by the Universal Exhibition in Paris in 1889 ; although this was not an electrical exhibition, the electrical exhibits formed such a large and important part that they may well be said to have formed the equivalent of an electrical exhibition. This was followed by the one at Frankfort, held this year, which forms the sixth and last, and which is to be followed by the electrical section of the World's Fair in 1893, making the seventh. Among the electrical exhibits made at exhibitions prior to the Paris Exposition of 1881 may be noted the first exhibit of the telephone, and a few arc lights run with a Gramme dynamo, both at the Centennial Exhibition in Philadelphia, in 1876; also a very small electrical exhibit, chiefly of telegraph instruments and apparatus, at the Paris Universal Exhibition of 1878.

The most prominent features at the electrical exhibitions were as follows: In the first one at Paris, in 1881, the chief feature was what might be called the birth of the present electrical industry. The most prominent exhibits included large dynamos of proportions thus far unknown; practical systems of distribution of arc lamps in series, and incandescent lamps in multiple arc, and practical systems of telephonic distribution. In Munich, 
the most prominent feature was the electrical transmission of power, about which so much was written, though so little was accomplished. In Vienna, in 1883, and in Philadelphia, in 1884, there were no particularly prominent features, electrical engineering having by that time developed into a steadily growing industry, as distinguished from one developing with spasmodic strides as in the previons years. In Paris, in 1889, the prominent feature ought to have been alternating current distribution, but owing probably to the absence of certain American and Austrian exhibitors, such systems were not as prominent there as their importance and their development at that time would have warranted. The alternating current apparatus of Professor Thomson and his welding machinery were unquestionably the most interesting novel features at this exhibition. At the Frankfort Exhibition, the most prominent feature was very high tension alternating current transmission, and alternating current motors. What the World's Fair has in store for us is to be seen, but electrical traction will doubtless be among the most prominent of the later developments in the electrical industry.

The two exhibitions in Paris were truly international in character; but in the others, except perhaps in the one at Vienna, there were so few exhibits from foreign nations that they can hardly claim to have been more than national exhibitions.

International electrical congresses were held in Paris in 1881 and 1889, in Philadelphia in 1884, and in Frankfort in 1891; of these, the first did the very creditable work of laying down the admirable system of electrical units and names which stands today as the most simple, rational and uniform system of complex units of measurement existing in any branch of engineering. The third congress, in 1889, also did good work in the field. The one in Philadelphia in 1884, and in Frankfort this year, accomplished practically no international work, leaving all the more to be done at the fifth congress, to be held in Chicago, in 1893.

The Frankfort Electrical Exhibition was started, I understand, by the electrical society of that city; it was conducted by some of the leading business men and electricians of that city, and, I believe, with some assistance or recognition from the government. It was therefore more of a private rather than a national enterprise. In Frankfort the foreign exhibits were limited to a very few, chiefly from Switzerland, England and the United States; it can not, therefore, lay much claim to having been international; 
it certainly was not, so far as representing the state of the art in other countries was concerned. It was an excellent exhibition of the state of the industry in Germany, but that was all.

The general arrangement of the grounds. buildings and exhibits was very creditable. The grounds and most of the buildings were attractively arranged, with a view to giving it a pleasing appearance and making it an attractive resort for the public, with as many "side shows" as possible, for which, however, an extra admission was charged. The average price of admission being only 18 cents, and on Sundays 5 cents, it was visited largely by persons who came there for the amusement, more than for studying the exhibits. I mention this because without these attractive features it could not have been a financial success. The number of visitors during the six months was somewhat over a million. The attraction afforded by some of the "side shows" may be judged from the fact that of the visitor's at the exhibition, one out of every three visited the panorama, a painting of a transatlantic steamer entering New York Harbor; the only electrical feature about it was that in the evening it was lighted by electricity.

Among the popular attractions on the ground, may be mentioned the following: A moderate-sized theatre with electric illumination from accumulators, and a very complete system for manipulating the lights to produce stage effects. Popular and very fully illustrated lectures were given here every afternoon, while in the evening there was a performance consisting of a pantomime or ballet, in which the plot was a senseless, though otherwise amusing mixture of mythology and of the history of electricity from the frog experiments to the crowning glories of the electric light. In a miniature model theatre, the firm of Siemens and Halske exhibited a very complete system of stage illumination, capable of producing very varied and really beautiful stage effects. This exhibit was a very successful one, and leaves no doubt that electric light is not only the best, but also the only means for producing such fine illumination effects on the stage. Many of these effects could not have been produced with gas or calcium lights, not to speak of the danger of fire attending such an attempt. The imitation of the sunset, the alpine glow and the rising of the moon, were particularly fine and in some respects fully equalled those of nature

On the grounds was an artificial waterfall pumped electrically 
from the river, with both direct and alternating current motors, and illuminated internally and externally with hidden colored electric lights. The internal illumination was not a success, as had been demonstrated before, both at Paris in 1889, and at Philadelphia in 1884, but the external illumination was quite fine and attractive, though hardly comparable with the really beautiful effects produced in the illuminated fountains in Paris in 18:9, by an English firm. The total illumination of the grounds and buildings was somewhat over a million candles. In the telephone building there was a long-distance transmission from the Opera House at Munich, a distance of about 200 miles. Male and female voices could be distinguished from each other, and sometimes even the different instruments of the orchestra. Besides this long-distance transmission. there were also several others trom music halls and theatres in the environs, in which the transmissions were very good.

Among the minor popular attractions were the following: A diver working under water by electric light; a sort of artificial race course for children, in which each horse was operated by a separate motor under the track, controlled from a common platform; an artificial mine, underground, with mining drills, pumps, ventilators and a small railroad; electric elevators, railroads and launches, etc; a boat with a benzine engine, both made entirely of aluminium produced by an electric process. One of the attractions greatly appreciated by the public was not electrical at all, being a series of workshops in active operation, for the manufacture of goods of all kinds, in which the only electric feature was that the machinery was driven by electric motors.

These popular exhibits, together with two typical German attractions, viz., excellent music and the numerous "Bier Hallen" formed the chief features for the public. On the other hand, the exhibition was by no means without attractions for the electrical engineer; the exhibits which interested him, far outnumbered those for the public. It may be said, however, that with the exception of a few exhibits, there was little shown which was not already known to the engineer through the foreign and domestic electrical journals. In these days of enterprising journalism, there is probably little of novelty in the electrical industry which does not find its way into the journals. The electrical juurnals of to-day may be said to form our permanent 
electrical exhibition. Although most of the exhibits were already known to the engineer, through their published description, it was nevertheless very interesting to see them, and examine them in operation. It was in this feature that the exhibition was most interesting to the engineer, and for this reason a description, such as could be given here, is a poor substitute for a visit to the exhibition itself. I will therefore confine myself here, merely to some general statements, leaving detailed descriptions to the journals, where they more properly belong and where many of them have already appeared.

In general, and with but few exceptions, there was one very noticeable feature to an American about the exhibits, and one that is to a certain extent characteristic of the two nations. The Germans are very careful, thorough, indefatigable workers; their work shows thought, intelligence and a thorough knowledge of the underlying principles (though not necessarily knowledge of what has been done outside of their own country), but they appear to lack invention. They will work out with much trouble and care, the best theoretical conditions (which sometimes lead them to impracticable constructions), but they lack the faculty of invention which suggests new practical conditions and simple ingenious contrivances. The Americans, on the other hand, possess the faculty of invention to a great degree, but their inventions and ideas, although bright and ingenious, not infrequently show the want of a fundamental and thorough knowledge of the subject, or a want of study and care in carrying them out. The numerous rejected or absurd ap lications in our patent office will show this. These statements are, however only quite general, there are of course many notable exceptions in both cases. In general, therefore, it may be said that there was a noticeable absence of novelties among the exhibits at this exhibition, but, on the other hand, the exhibits showed careful, intelligent and very creditable work.

There was another notable feature which has its parallel, to a certain extent, in the watch industry. In America the electrical industry has developed to such a degree that dynamos and motors are made from the same templates, and probably often with interchangeable parts. They are kept in stock, and installations must be made to suit these standard sizes. I am told that in one of our largest factories, anything different from the regular standard sizes or designs is undertaken with great reluctance and 
little interest. In Germany, on the other hand, the dynamos, I am told, are as a rule made to suit the installations, and are varied in design to suit the requirements. In numerous cases in which I wished to find out what their usual practice was, it turned out that there was no usual practice; that the exhibit was the first, or among the first of its kind made. In a pattern shop of one of the largest companies, I noticed about six different patterns for very large dynamos all for about the same output, which had been used for only a few castings, and some for only one. Yet they state that they make a profit, even though the dynamos are very much cheaper than in the United States, while they are often fully as good, if not better. While the one system is more flexible and undoubtedly leads to a more perfect development of the dynamo, the other, although it does to a certain extent retard development, is unquestionably the most practical method when the sales are large, and it will no doubt be employed there when the industry assumes the proportions it has assumed here.

There was still another feature which was noticed, and I mention it here, not with mere fault-finding intentions, but with the hope that we may correct a fault which we must admit does exist, to a certain extent, at least. In America there is sometimes a tendency to sacrifice quality of work for quantity, which is a natural result of the objectionable practice of awarding a contract to the lowest bidder, and it is, therefore not necessarily a fault of the manufacturers. In Germany, much pride is taken in making and keeping one's reputation for doing good work; so much so, that the name of a company and the quality of the work they have done has perhaps more weight in awarding a contract than the price. The natural result is that the work is more creditably and carefully done; there is a greater variety in the systems used, and they are better adapted to suit the special requirements of the particular installations. A noticeable feature to show the preference for substantial work is seen in one of the accumulators exhibited. Here in America the tendency has been to get the greatest possible output per pound of weight, or in other words to put in as little material as possible; the result is that the accumulator here is a frail, delicate object which must be accompanied by a nurse, or its life will not be guaranteed by its maker. In Germany they have discarded this policy to a great extent. The accumulator which is used there most frequently, and much more in proportion than accumulators are used here, 
is a strong, heavy, hardy, Planté cell, with plates so thick that they are able to stand without being watched so carefully. The result of this is, that there are many installations and central stations there equipped with accumulators. I call attention to this particular case, as there is no doubt that in the application of storage batteries to central stations they are far ahead of us, and we can learn much from them.

Regarding the nature of the recent progress in the electrical industry as exhibited there, it may be said that, excepting the rotary current systems, there was no radically new departure shown in any of the prominent branches. The exhibits, as a rule, showed that the erratic progress made in the earlier years, was being replaced by a steady, natural and healthy progress, such as may be expected in any important industry, receiving the attention that this one does. Impracticable and absurd ideas are dying a natural death, and the wholesome effects of the law of the survival of the fittest are plainly to be seen. Although the progress of the introduction of electric light and power in Germany, has been much slower than in the United States, it has been, and continues to be a steady progress; the Germans may think twice before they act, but when they do act they do their work well and thoroughly. New York was the first city to have a large local central station plant for incandescent lights in a small limited district, but Berlin will soon be ahead of New York if it is not so already, in having an extended, homogeneous, well-planned, underground system for supplying incandescent lights to a very large part of the city. The motive there is not to pay the greatest dividends, to speculate with franchises, or to supply politicians with boodle; their leading object is to supply the inhabitants with a reliable system of lighting, as cheap as is consistent with thoroughness. It is needless to say that in a wellregulated government like that of Germany, the government controls the companies, and does not allow itself to be controlled by them. In street lighting, and doubtless also in the distribution of power and the application of motors, they are far behind us, and can learn much from us, but in their manner of introducing complete systems of supplying light in their cities, we have much to learn from them.

Electric railroads on the continent were conspicuous by their almost total absence; yet the conduit system used in Budapest, in Hungary, which is probably the largest network of lines in 
Europe, is apparently one of the most satisfactory of any systems in use anywhere, here or abroad, at least where the appearance of the streets has any weight at all. One has only to compare a certain place in Budapest, where there are many crossings, curves and switches, with a similar place in Boston, to appreciate the difference from an æsthetic standpoint. The trolley wire is no doubt the best system for suburban and interurban lines, or for small towns; but in a large city, which takes any pride in its appearance, the trolley wire should and will give way to less hideous systems.

Proceeding now to the individual exhibits, it is not the place here to attempt to describe them in detail. I will confine myself here to mere general remarks, leaving detailed descriptions to the journals where they more properly belong.

The historical exhibits were quite naturally limited to those of Germans. Great prominence was given to Soemmering, as the original inventor of the telegraph in 1809 . His statue was seen in several places, and his original apparatus was exhibited in operation. The original apparatus of Reiss, the inventor of the telephone, the electric machine of Goethe, and the original apparatus of Hertz, were among the most interesting historical exhibits.

Among the many firms exhibiting, the most prominent was, no doubt, the firm of Siemens and Halske, the largest electrical manufacturers in Germany. Their field is apparently unlimited, -as they exhibited creditably in almost all the branches of the electrical industry. They appear to make a specialty of nearly every branch, and in some of them they unquestionably excelled. The firm of Schukert had the next largest exhibit; although not so broad in scope, it was in some respects possibly more creditable. "Helios," representing the Austrian firm of Ganz and Co., came next in order of size of their exhibit, which was limited entirely to alternating current machines and systems. The ex. hibits of these three firms, one at each end and one in the middle, occupied the greater half of the machinery hall. The Allgemeine Electricitæts Gesellschaft, of Berlin, and the Oerlikon Co., of Zurich, came next in point of prominence. Their joint exhibit of the high tension rotary current power transmission may be said to have excelled the others in point of interest, as it was undoubtedly the most interesting exhibit to the engineer, as well as the most novel. 
The exhibition of dynamos were, as a rule, very creditable, both as to workmanship, and particularly as to absence of sparking at the brushes. It can not be said that any one form predominated ; there was, in fact, probably a greater variety of form than at any other exhibition; there were scarcely two alike. A very noticeable feature was that all large machines were multipolar; large bipolar machines apparently do not exist in Germany, and in this respect they are doubtless ahead of us. Ore reason for this is, no doubt. that their large dynamos are almost without exception coupled directly to the engine. This leads to slow speeds, and consequently to armatures of large diameters, which, of course, excludes bipolar fields. In several prominent cases the armatures were outside of the radial multipolar fields, a practice which, I believe, is not attempted in this country at all. A happy medium between the two, appeared in the large flat ring armature of Schukert, which combines the advantages of both. The largest dynamo was that of Siemens and Halske, having ten radial poles, around the outside of which revolves a large Gramme ring armature, ten feet in diameter, whose external surface is bare and acts as the commutator. There are ten sets of brushes of three each, making thirty brushes to take care of. These dynamos have an output of 600 kilowatts at 100 revolutions, and are the units for their central stations, chiefly for those in Berlin. They state that about thirty of these have been installed. The large alternating current dynamos exhibited were made according to the old models, with radial magnets. A very serious objection to this form appears to be that the machines make a very loud humming noise, like a very low-tuned steam whistle. So loud was this noise that it made conversation difficult, and, in fact, almost impossible in the neighborhood of the large machine, for which reason it was called the "growler" of "grumbler" by the rival exhibitors. Among the more unusual forms of dynamos may be noted the Fritsche continuous current, and the Kingdon alternator, having no moving wire, both of which have been described in the electrical journals.

It appears that carbon brushes are limited chiefly to motors, and especially to railway motors, where they appear to have replaced the others entirely. The form of brush almost exclusively used for dynamos is one made of fine copper wire gauze; an important feature being that the fibres run diagonally and not crosswise. thereby avoiding a fraying out at the ends, which was 
formerly the great objection to them. The chief advantages of this brush are, that it is soft and does not "scream" like wire or foil brushes, and that it is easily made; it is strange that it is not adopted in this country. Bearings are, as a rule, made with selffeeding arrangements, like a ring or a wick having an oil reservoir below the bearing. Speeds are almost invariably low, and armatures large. Field magnets are generally very short and thick, a natural accompaniment of multipolar fields. Large dynamos are, as a rule, coupled directly to the engine. The workmanship on dynamos was, as a rule, very good, as was also the construction, apart from the design; the design was in a number of cases awkward and cumbersome.

Among the various systems of distribution exhibited, the simple 110-volt continuous current system still leads for isolated plants. Alternating current systems are not used for smaller plants, being chiefly limited to central stations. Arc lamps are, as a rule, run from the same mains as the incandescent, being connected two in series, together with a dead resistance. This resistance represents a dead loss of power, reaching as high as 20 and $2 \check{\jmath}$ per cent., but it is a necessary part of such a system, as the lamps often have shunt coils, which would be of no use as a source of regulation, if there were no resistance in series with the lamp. Whatever disadvantages attend such an arrangement, it must be said that the arc lamps burn far better there than here. Our restless, flickering lamps contrast very unfavorably with the average lamps seen at this, or at the late exhibition at Paris.

Although the amount of power represented by the alternating current systems was quite great, the number of exhibits of this system were comparatively small, as compared to the others, showing that the continuous current systems still predominate in Germany. The largest dynamos of the alternating type were those of the "Helios" Company (Ganz and Co.), and of the firm of Siemens and Halske. The "Helios" Company uses. 2,000 volts and about 83 alternations; arc lamps and small motors were run indiscriminately from their mains. The next most important system of distribution was the accumulator system, in connection with the three-wire distribution, an arrangement which I believe is seldom used here, though it seems to be quite common there, judging from the exhibits. In this system one or more dynamos of about 250 volts charge two sets of accumulators in series, each of about 125 volts. These are con- 
nected to the three mains of the three-wire system, the neutral wire being connected to the middle of the series. By means of switches connected to the outside cells, the voltage for the long and the short feeders may be made greater and less, respectively, and the cells may be cut out when fully charged.

The only important series system for arc lamps was an American exhibit by the Thomson-Houston Company. Such systems may truly be called American, as they do not appear to be used to any extent by the German or French companies, who seem to acknowledge that we are their superiors in this branch. The result of the neglect to develop this system is, that in European cities arc lamps are rarely seen in the streets, at least when we compare their streets to those of American cities.

The series incandescent system, I believe, was not represented at all at this exhibition. It also may be called a truly American system. The five-wire system was represented, but it failed to leave a favorable impression, and, as far as I could ascertain, it is in use in a central station in only one city, the home of the company advocating the system. This fact speaks for itself.

Among the systems of distribution of power, may be mentioned above all, the rotary field system of the Lauffen-Frankfort exhibit. It is truly a system of distribution as compared to a mere system of transmission. Next in interest were the alternating current motors, run from the "Helios" Company's system. They were mere alternating current machines, with a rectified current in the field, obtained from a commutator. They appear to have a dead point, at which they will not start. They make some noise at starting, and there are more or less brilliant arcs at the commutator until they run synchronously, but after that they appear to run well. Motors from 1 to 5 H. P. will start in from 6 to 28 seconds.

Among the systems of simple transmission of power, as distinguished from systems of distribution, the largest was a 2,000 volt continuous current system exhibited by Lahmeyer. The receiver in this system was an ingenious continuous current transformer of the motor dynamo type. The system of switches for starting, controlling and regulating the power, and for protecting the apparatus as well as the attendants, was very complete and very creditable to the designer, but the whole system failed to show any material advantages over the alternating current systems; on the contrary, it left the impression that it was 
inferior. Besides these systems there were also a few motors run with a two-phase rotary field current using four wires, by Schuckert. These motors were started unloaded, and without a field current; the latter, obtained from a commutator, was swit hed on when the motor had reached synchronism.

The exhibits of electric railroads were meagre, and, with one exception (the Budapest system), they were unsatisfactory to an American, as they were experimental systems, as distinguished from normal systems. In this branch they have much to learn from us.

Among the transformers, there was apparently nothing of particular interest. The firm of "Helios" have abandoned the old form of Zipernowsky-Deri (for Faraday) transformers, and have adopted one like the usual forms, in which the disposition of the coils is a more practical one. Motor dynamo transformers, or dynamotors, were quite frequently seen, and appeared to be used very much more frequently than here.

Note.-The remainder of the paper was a verbal description of some of the more prominent exhibits, accompanied by slides showing a number of interior and exterior views of the grounds and buildings, and detailed views of some of the exhibits, more particularly of the Lauffen-Frankfort transmission experiment, most of which have been published in the foreign and domestic journals, and are therefore omitted here at the suggestion of the author.-EDrTor. 